\title{
Amino Derivatives of Mannuronic Acid
}

\author{
By Harriet L. Frush and Horace S. Isbell
}

\begin{abstract}
A new type of sugar derivative that may prove to be of value in synthetic processes has been prepared from mannuronic lactone by reaction with ammonia. The structure of the new substance, 1-aminomannuronamide, has been determined, and certain crystalline derivatives have been prepared.
\end{abstract}

\section{Discussion}

The widespread occurrence of amino derivatives of the sugars in products of plant and animal origin suggests the possibility that amino derivatives of the uronic acids may likewise be of importance. The uronic acids have the characteristic structures of both aldoses and aldonic acids, and hence, like the aldoses, might be expected to yield glycosyl amines [1] ${ }^{2}$ and like the lactones of the aldonic acids, to yield amides [2].

When mannuronic lactone was treated with ammonia in methanol in an endeavor to obtain the amide, a crystalline compound having the formula $\mathrm{C}_{6} \mathrm{H}_{12} \mathrm{O}_{5} \mathrm{~N}_{2}$ separated from solution. The new compound, which has been found to be 1-aminomannuronamide crystallizes very readily and is suitable for the identification of mannuronic acid. It is fairly soluble in water, but aqueous solutions are somewhat unstable, and slowly hydrolyze with evolution of ammonia.

On prolonged treatment with excess dilute acid, the optical rotation of a solution of 1-aminomannuronamide gradually changed from the levo to the dextro direction and attained the same value as that of a solution of mannuronic lactone similarly treated. Subsequently, mannuronic lactone was isolated from the solution. It is known that amino derivatives of the sugars in which the substitution is on an alcoholic carbon are extremely resistant to hydrolysis. Hence, the two amino groups in the new compound are not combined with the alcoholic carbons, and the

1 This paper was presented before the Division of Sugar Chemistry and Technology of the American Chemical Society at Chicago, Ill., April 21, 1948.

2 Figures in brackets indicate the literature reference at the end of this paper. crystalline substance must have one of the following structures, of which the pyranose (I) seems most probable:<smiles>CC(C(N)=O)C(O)C(O)C(N)CO</smiles><smiles>NC(=O)C(O)CCOCC(N)C(O)CO</smiles><smiles>N=CC(O)C(O)C(O)C(O)C(N)=O</smiles>

III.

When dissolved in water, 1-aminomannuronamide exhibits a fairly rapid mutarotation over the course of $2 \mathrm{hr}$; this is followed by a slow change during several days. Presumably the former is caused by an interconversion of the various modifications of the sugar entity, and the latter by a gradual hydrolysis of the amino group. The system is greatly affected by experimental conditions, and the mutarotation is being investigated further.

On acetylation with acetic anhydride in pyridine, 1-aminomannuronamide gave two crystalline products, one of which was dextrorotatory and one levorotatory. The quantity of the dextrorotatory 
product obtained was too small to permit extensive study, but the analysis and properties of the two products show that they are isomeric; presumably they differ merely in configuration or in ring structure. A condensation product analogous to the diglucosylamine acetate that Brigl and Keppler obtained from glucosylamine by treatment with acetic anhydride and pyridine [3] was expected but could not be found.

The levorotatory acetate, the principal product of the reaction, was shown by analysis to have three $O$-acetyl groups and one $N$-acetyl group. Because amide nitrogen is not readily acetylated, it can be assumed that the $N$-acetyl is attached to the glycosylamino group, and that the compound is $1-N$-acetylamino-triacetylmannuronamide (or 1-acetamido-triacetylmannuronamide).

Deacetylation of the 1-N-acetylamino-triacetylmannuronamide by the barium methylate method [4] gave a monoacetate that was obtained in the crystalline state. The resistance of one acetyl group to hydrolysis by barium methylate shows that it is attached to nitrogen. The acetylamino group of the monoacetate is more stable to hydrolysis than the free amino group in the original 1-aminomannuronamide, and no decomposition or change in optical rotation at room temperature was observed in an aqueous solution of the compound during a period of several hours. Presumably the acetylamino group has little tendency to undergo isomeric change through the Schiff base. $1-N$-acetylaminomannuronamide is readily oxidized by periodic acid and consumes 2 moles of the oxidant per mole of compound. The reaction appears analogous to that of $N$-acetylglucopyranosyl amine [5], which on periodate oxidation yields the dialdehyde

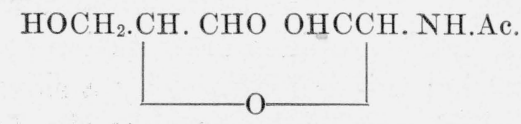

Since 2 moles of periodate were consumed in the present case, $1-N$-acetylaminomannu ronamide has a pyranose ring and can be assigned the structure represented in formula IV.<smiles>CC(C(N)=O)C(O)C(O)C(O)CN</smiles><smiles>CCNC(C)C(OC)C(OC)C(C)OC</smiles>

The evidence for this structure is conclusive. Presumably the parent acetate has an analogous structure (formula $\mathrm{V}$ ) and is $1-\mathrm{N}$-acetylamino-2,3,4-triacetylmannuronamide. The structure of the latter substance however is not rigidly established, because a shift in the ring may have taken place during deacetylation. Obviously a change in structure takes place in passing from mannuronic lactone, which is known to have a furanose ring [6], to 1- $N$-acetylaminomannuronamide, which has now been shown to have a pyranose ring.

\section{Experimental}

\section{1-Aminomannuronamide}

Ten grams of finely divided mannuronic lactone was suspended in $200 \mathrm{ml}$ of anhydrous methanol in an Erlenmeyer flask, and a stream of dry ammonia gas was passed into the liquid. The temperature of the reaction mixture was maintained at $20^{\circ} \mathrm{C}$ or less by cooling in a cold-water bath. The lactone dissolved, and shortly after dissolution a crystalline substance began to separate. When crystallization was substantially complete (about $1 \mathrm{hr}$ ) the stream of ammonia gas was interrupted, and the material was allowed to stand first at room temperature for a few hours and then in a refrigerator for $24 \mathrm{hr}$. The crystals of 1-aminomannuronamide were collected on a filter, washed with methanol containing ammonia, and finally with methanol alone; the yield was 9.0 g. A second crop of crystals formed when the mother liquor was kept in the refrigerator for several days and made the total yield nearly quantitative.

1-Aminomannuronamide was recrystallized by dissolving it in 15 parts of concentrated ammonium hydroxide at approximately $40^{\circ} \mathrm{C}$, filtering the solution, and adding absolute ethanol nearly to the point of turbidity. The solution was seeded and allowed to stand in a glass-stoppered flask in the refrigerator. After $24 \mathrm{hr}$, the crystals that had formed were collected on a filter, washed with ethanol containing ammonia, and dried at room temperature in a vacuum desiccator. The yield was approximately 90 percent. The re- 
crystallization was repeated in the same manner, and the resulting product gave the following analysis: Calculated for $\mathrm{C}_{6} \mathrm{H}_{12} \mathrm{O}_{5} \mathrm{~N}_{2}$ : C, 37.50; H, 6.29 ; N, 14.58; Found: C, 37.4; H, 6.3; N, 14.6. 1-Aminomannuronamide crystallizes in colorless many-sided prisms (fig. 1, A). It is difficultly soluble in methanol, ethanol, acetone, and pyridine, and moderately soluble in water; but in aqueous solution it decomposes over the course of many days with the evolution of ammonia. The melting point (decomposition point) is indefinite. Sintering, darkening, and decomposition with evolution of gas occur at temperatures between $145^{\circ}$ and $170^{\circ} \mathrm{C}$, but the values depend greatly upon the rate of heating. In 1.5-percent aqueous solution, 1-aminomannuronamide gave the mutarotation reported in table 1.
TABLE 1. Mutarotation of 1-aminomannuronamide

\begin{tabular}{|c|c|c|}
\hline \hline \multicolumn{3}{|c|}{$0.4000 \mathrm{~g}$ in $\begin{array}{c}25-m l \\
\text { read in a 4-dm tube }\end{array}$} \\
\hline Time & $\circ S$ & {$[\alpha]_{D}^{20}$} \\
\hline & & \\
\hline Minutes & & \\
4.2 & -9.50 & -51.39 \\
9.8 & -9.40 & -50.85 \\
46.0 & -9.11 & -49.28 \\
76.0 & -8.99 & -48.63 \\
136 & -8.83 & -47.74 \\
226.0 & -8.71 & -47.12 \\
301.0 & -8.66 & -46.84 \\
376.0 & -8.60 & -46.52 \\
1,380 & -7.91 & -42.79 \\
2,940 & -6.85 & -37.05 \\
4,380 & -5.95 & -32.08 \\
& & \\
\hline
\end{tabular}

When the compound was treated with an excess of dilute acid at elevated temperatures, the optical

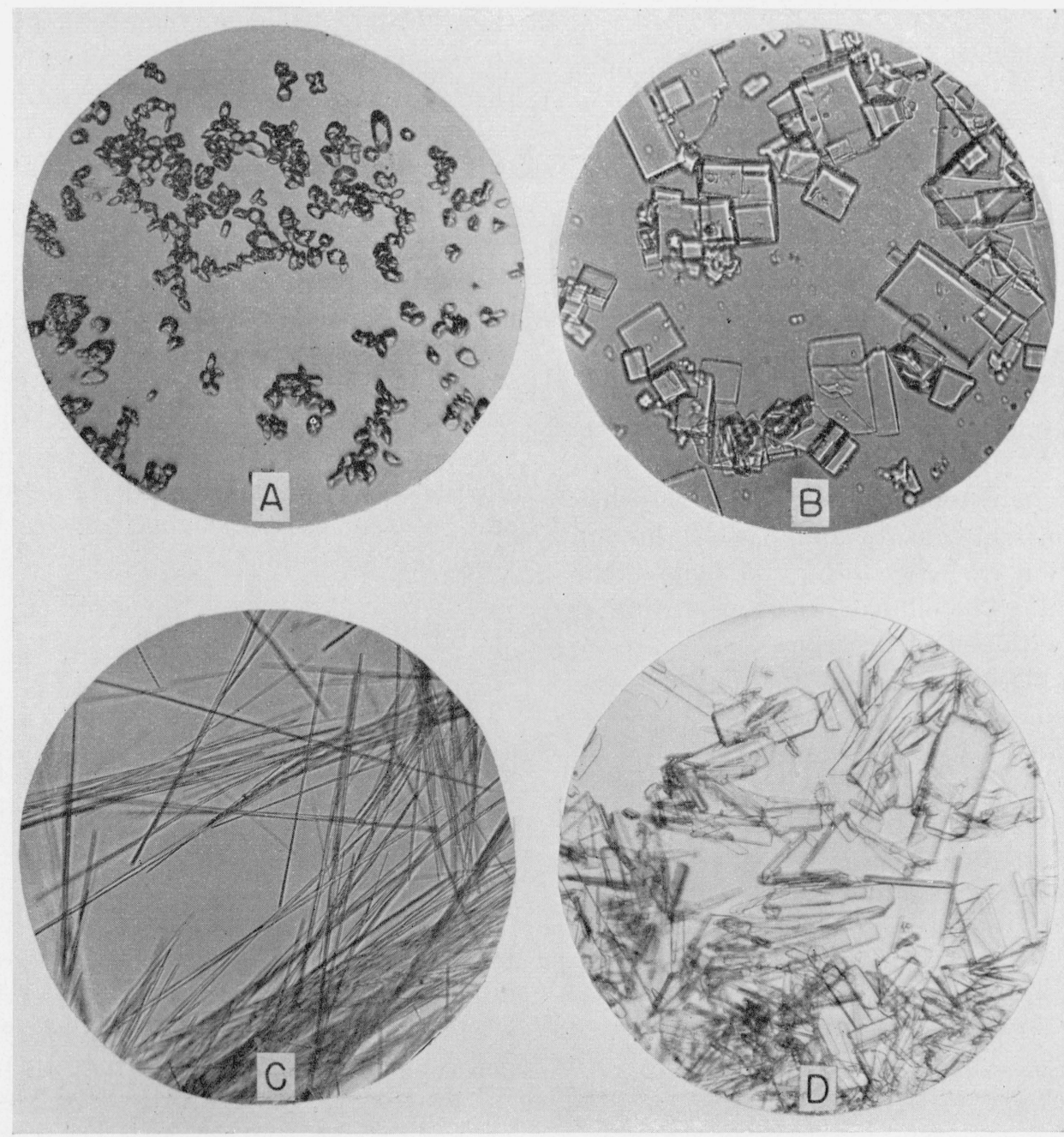

FIGURE 1. Photomicrographs of amino derivatives of mannuronic acid.

A, 1-Aminomannuronamide; B, 1-N-acetylamino-2,3,4-triacetylmannuronamide; C, 1- $N$-acetylaminomannuronamide (anhydrous); D, 1- $N$-acetylaminomannuronamide (hydrate) 
rotation approached a constant value that was substantially that of an equimolecular solution of mannuronic lactone similarly treated. A $0.2008-\mathrm{g}$ sample of 1-aminomannuronamide was dissolved in $25 \mathrm{ml}$ of $0.1011 \mathrm{~N} \mathrm{HCl}$, and the solution was kept in a sealed container at $60^{\circ} \mathrm{C}$ and then at $100^{\circ} \mathrm{C}$ for the time intervals shown in table 2 . The optical rotations $\left({ }^{\circ} \mathrm{S}\right.$ in a $2-\mathrm{dm}$ tube, measured at $20^{\circ} \mathrm{C}$ ), are given in column 3 . Corresponding changes for an equimolecular solution of mannuronic lactone $(0.1840 \mathrm{~g}$ in $25 \mathrm{ml})$ are shown in column $4 .^{3}$

TABLE 2. Effect of dilute acid at elevated temperatures on the optical rotation of 1-aminomannuronamide and mannuronic lactone

\begin{tabular}{|c|c|c|c|}
\hline \multirow[b]{2}{*}{ Time } & \multirow{2}{*}{$\begin{array}{l}\text { Tempera- } \\
\text { ature of } \\
\text { heating }\end{array}$} & \multicolumn{2}{|c|}{$\begin{array}{l}\text { Rotation of solution derived } \\
\text { from }\end{array}$} \\
\hline & & $\begin{array}{c}\text { 1-Aminoman- } \\
\text { nuronamide } \\
\text { or }(2-\mathrm{dm} \\
\text { tube })\end{array}$ & $\begin{array}{l}\text { Mannuronic } \\
\text { lactoneb, } \\
\text { oS (2-dm } \\
\text { tube) }\end{array}$ \\
\hline$h r$ & ${ }^{\circ} \mathrm{C}$ & & \\
\hline 18 & 60 & +1.62 & +1.91 \\
\hline 2 & 100 & 1.85 & \\
\hline 18 & 100 & 2. 09 & 2. 10 \\
\hline
\end{tabular}

a $0.2008 \mathrm{~g}$ of 1-aminomannuronamide in $25 \mathrm{ml}$ of $0.1011 \mathrm{~N} \mathrm{HCl}$. b $0.1840 \mathrm{~g}$ of mannuronic lactone in $25 \mathrm{ml}$ of $0.0175 \mathrm{~N} \mathrm{HCl}$.

In a separate experiment, mannuronic lactone was isolated from the hydrolyzate. One gram of 1-aminomannuronamide was dissolved in 125 $\mathrm{ml}$ of $0.1011 \mathrm{~N} \mathrm{HCl}$, and the solution was kept at a temperature of $100^{\circ} \mathrm{C}$ for $18 \mathrm{hr}$. It was then cooled to room temperature and passed through a column of ion exchange resin ${ }^{4}$ to remove the ammonium ion. The effluent was cooled to $0^{\circ} \mathrm{C}$ and treated with sufficient silver carbonate to remove the chloride ion, and the mixture was filtered immediately through a layer of decolorizing carbon. The filtrate was again passed through a column of cation exchange resin to remove silver ion, and the effluent was concentrated under reduced pressure and finally in air to a sirup from which the characteristic crystals of mannuronic lactone separated spontaneously. The crude

\footnotetext{
${ }^{3}$ As 1-aminomannuronamide reacts during hydrolysis with two equivalents of acid, the mannuronic acid entity is subjected to acid of varying strength during the hydrolysis. The sample of mannuronic lactone was treated with acid whose concentration was equal to that at the end of the hydrolysis of the 1-aminomannuronamide $(0.0175 \mathrm{~N})$

${ }^{4}$ Amberite IR-100-H, Resinous Products and Chemicals Co., Philadelphia, Pa.
}

crystals were collected on a weighed Gooch crucible, washed with acetic acid, and dried in a vacuum desiccator over sodium hydroxide; they weighed $0.70 \mathrm{~g}$. After one recrystallization from aqueous acetic acid, the product was identified as mannuronic lactone by specific rotation $\left([\alpha]_{D}^{20}=\right.$ $+91.6^{\circ}$, (water, $\mathrm{c}=4,30$ minutes after dissolution). For mannuronic lactone, $[\alpha]_{D}^{20}=+92.2^{\circ}$ under the same conditions.

\section{1- $N$-Acetylamino-2,3,4-triacetylmannuronamide}

A mixture of $5 \mathrm{~g}$ of finely powdered 1-aminomannuronamide, $50 \mathrm{ml}$ of pyridine, and $20 \mathrm{ml}$ of acetic anhydride, in a flask equipped with a mechanical stirrer, was kept in an ice bath and stirred for a period of 2 days; it was then allowed to stand at room temperature for 2 days. After the addition of an equal volume of petroleum ether to the mixture, the crystals that had formed during the acetylation were collected on a funnel, washed with petroleum ether and dried in a vacuum desiccator. The yield of the crude acetate was $6.5 \mathrm{~g}$. This material was dissolved in $600 \mathrm{ml}$ of boiling acetone, and the solution was treated with a decolorizing carbon, filtered, and concentrated under reduced pressure to approximately $300 \mathrm{ml}$. After standing for $2 \mathrm{hr}$, it yielded thick rectangular plates (fig. 1B), which weighed $4 \mathrm{~g}$, dried in a vacuum desiccator. The crystals melted with decomposition at $264^{\circ}$ to $267^{\circ} \mathrm{C}$. $[\alpha]_{D}^{20}=-7.8^{\circ}$ (methanol, $\mathrm{c}=1$ ). The melting point and specific rotation were unchanged by further crystallization from acetone.

Analysis: Calculated for $\mathrm{C}_{14} \mathrm{H}_{20} \mathrm{O}_{9} \mathrm{~N}_{2}$ : C, 46.66; $\mathrm{H}, 5.60 ; \mathrm{N}, 7.78$; total acetyl, 47.79; O-acetyl, 35.84. Found: C, 46.8; H, 5.7; N, 7.9; total acetyl, $48.0 ; O$-acetyl, $34.2 .^{5}$

The mother liquor of the crude acetate yielded a mixture of rectangular plates and fine needles weighing $2.4 \mathrm{~g}$ and having a specific rotation of $-1.3^{\circ}$. This material was triturated with 50 $\mathrm{ml}$ of dioxane, and the dioxane extract, when evaporated to dryness, yielded a small crop of needle crystals. After recrystallization from methanol this material had a high dextrorotation $\left(+62^{\circ}\right)$ and gave an analysis corresponding to

\footnotetext{
${ }^{5}$ Total acetyl was determined by the method of Elek and Harte [7]. 0 acetyl was determined by the method of Kunz [8] as employed by Wolfrom and coworkers [9].
} 
$N$-acetylamino-triacetylmannuronamide. The substance, although not entirely pure, appears to be isomeric with the levorotatory $N$-acetylaminotriacetylmannuronamide.

\section{1-N-Acetylaminomannuronamide}

$\mathrm{N}$-Acetylamino-triacetylmannuronamide $(4.8 \mathrm{~g})$ was dissolved in $250 \mathrm{ml}$ of anhydrous methanol, and the solution was treated with $10 \mathrm{ml}$ of $1.5 \mathrm{~N}$ barium methylate [4]. After 10 minutes, $500 \mathrm{ml}$ of water was added, and the solution was filtered successively through columns containing cation and anion exchange resins. The filtrate was treated with a decolorizing carbon, refiltered, and concentrated under reduced pressure to a thin sirup. Methanol was added, nearly to the point of turbidity. Long needle-like crystals formed quickly and after standing at room temperature overnight were separated, washed with methanol, and dried in a vacuum desiccator over calcium chloride. The yield, $3.1 \mathrm{~g}$, was nearly quantitative. The compound was recrystallized by dissolving it in hot anhydrous methanol, filtering the solution, and allowing crystallization to occur at a temperature of $30^{\circ} \mathrm{C}$. The crystals that formed (fig. 1, C) were separated, washed with methanol, and air-dried at room temperature. The product sintered at $208^{\circ} \mathrm{C}$. and melted with decomposition at $210^{\circ}$ to $212^{\circ}$ C. $[\alpha]_{D}^{20}=-76.2^{\circ}$ (water, $\mathrm{c}=2$ ). The constants were unchanged by further recrystallization.

Analysis: Calculated for anhydrous $\mathrm{N}$-acetylaminomannuronamide $\mathrm{C}_{8} \mathrm{H}_{14} \mathrm{O}_{6} \mathrm{~N}_{2}$ : C, 41.02; $\mathrm{H}$, $6.03 ; \mathrm{N}, 11.96 ; \mathrm{CH}_{3} \mathrm{CO}, 18.38$. Found: $\mathrm{C}, 41.0$; $\mathrm{H}, 6.2 ; \mathrm{N}, 12.0 ; \mathrm{CH}_{3} \mathrm{CO}, 18.3$.

When crystallized at low temperatures from a larger amount of water by the addition of methanol and isopropanol, $\mathrm{N}$-acetylaminomannuronamide separated in the form of large transparent thin prisms (fig. 1, D), which appeared to be a somewhat unstable hydrate. On standing in a desiccator over calcium chloride, the crystals became opaque, lost weight, and were gradually converted to the anhydrous form.

When $N$-acetylaminomannuronamide was oxidized with $0.25 M$ periodic acid, there was a rapid increase in levorotation over the course of 30 minutes, after which the rotation decreased slowly. A solution that was $0.1 M$ with respect to
$N$-acetylaminomannuronamide, and $0.25 \mathrm{M}$ with respect to periodic acid was allowed to stand at $20^{\circ}$ C. for 30 minutes. Excess periodic acid was determined by neutralizing an aliquot $(10 \mathrm{ml})$ with sodium bicarbonate, adding an excess of a $0.1 \mathrm{~N}$ solution of sodium arsenite $(25 \mathrm{ml})$ and of a 20-percent solution of potassium iodide $(1 \mathrm{ml})$, and titrating the excess arsenite with a $0.1 \mathrm{~N}$ solution of iodine. The result showed that 2.1 moles of periodic acid had been consumed per mole of $\mathrm{N}$-acetylaminomannuronamide. There appeared to be a gradual fading of the end-point in the titration of the arsenite with iodine. It is believed that this peculiarity may be associated with the presence in the dialdehyde of a conjugated bond system that is particularly susceptible to oxidation. This subject is being investigated further.

\section{Summary}

Mannuronic lactone, when suspended in methyl alcohol and treated with ammonia was found to yield crystalline 1-aminomannuronamide, $\mathrm{C}_{6} \mathrm{H}_{12} \mathrm{O}_{5} \mathrm{~N}_{2},[\alpha]=-43.8^{\circ}$ (water, $\mathrm{c}=1.5,5 \mathrm{~min}$ after dissolution). The substance exhibits mutarotation with a fairly rapid decrease in levorotation for $2 \mathrm{hr}$, followed by a slow decrease over the course of many days. By heating with dilute aqueous acid, both nitrogens were removed, and mannuronic lactone was separated from the hydroJyzate. Since amino groups attached to carbons $2,3,4$ and 5 would be resistant to hydrolysis, the nitrogen substitution must be on carbons 1 and 6 as required for 1-aminomannuronamide.

Acetylation of 1-aminomannuronamide with acetic anhydride in pyridine gave two crystalline acetates, one dextrorotatory, one levorotatory. Analyses showed them to be isomeric compounds having the formula $\mathrm{C}_{14} \mathrm{H}_{20} \mathrm{O}_{9} \mathrm{~N}_{2}$. The principal product, the levorotatory acetate, melts at $264^{\circ}$ to $267^{\circ} \mathrm{C} . \quad[\alpha]_{D}^{20}=-7.8^{\circ}$ (methanol, $\mathrm{c}=1$ ).

This acetate was deacetylated by barium methylate and yielded crystalline $1-N$-acetylaminomannuronamide $\mathrm{C}_{8} \mathrm{H}_{14} \mathrm{O}_{6} \mathrm{~N}_{2}$, melting point $210^{\circ}$ to $212^{\circ}$ C. $[\alpha]_{D}^{20}=-76.2^{\circ}$ (water, $\mathrm{c}=2$ ). The substance also crystallized in the form of a hydrate. One mole of $1-N$-acetylaminomannuronamide reacts with 2 moles of periodic acid. This fact shows that the substance has a pyranose structure. Presumably the parent tetraacetate is likewise a 
pyranose, but this is not established because a shift in ring structure may have taken place during deacetylation.

The authors gratefully acknowledge the assistance of Nancy B. Holt in various phases of the work, and of Rolf A. Paulson who analyzed the compounds reported.

\section{References}

[1] C. A. Lobry de Bruyn and A. P. N. Franchimont, Rec. trav. chim. 12, 286 (1893); C. A. Lobry de
Bruyn and F. H. Van Leent, Rec. trav. chim. 14, 129 (1895).

[2] R. A. Weerman, Rec. trav. chim. 37, 1 (1917).

[3] P. Brigl and H. Keppler, Z. physiol. Chem. 180, 38 (1929).

[4] H. S. Isbell, J. Research NBS 5, 1185 (1930) RP253.

[5] C. Niemann and J. T. Hays, J. Am. Chem. Soc. 62, 2960 (1940).

[6] H. S. Isbell and H. L. Frush, J. Research NBS 37, 1 (1946) RP1727.

[7] A. Elek and R. A. Harte, Ind." and_Eng. Chem., An. Ed. 8, 267 (1936).

[8] A. Kunz, J. Am. Chem. Soc. 48, 1982 (1926).

[9] M. L. Wolfrom, M. Konigsberg and S. Soltzberg, J. Am. Chem. Soc. 58, 490 (1936).

Washington, April 14. 1948. 